\title{
Subconjunctival adalimumab for treatment of dry eye disease in Sjögren's syndrome
}

\author{
Tratamento de olho seco com adalimumabe subconjuntival \\ em pacientes portadores da síndrome de Sjögren
}

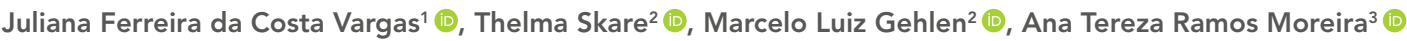

${ }^{1}$ Hospital Universitário Evangélico Mackenzie, Curitiba, PR, Brazil. ${ }^{2}$ Hospital Universitário Evangélico Mackenzie, Curitiba, PR, Brazil ${ }^{3}$ Universidade Federal do Paraná, Curitiba, PR, Brazil.

\section{Vargas JF, Skare T, Gehlen ML, Moreira AT. Subconjunctival adalimumab for treatment of dry eye disease in Sjögren's syndrome; Rev Bras Oftalmol. 2022:81:e0003.}

https://doi.org/10.37039/1982.8551.20220003

Keywords:

Adalimumab; Sjögren's syndrome; Dry eye syndromes;

Tumor necrosis factor-alpha;

Therapeutics

Descritores:

Adalimumab; Síndrome de Sjogren; Síndromes do olho seco; Fator de necrose tumoral alfa; Terapêutica

Received on: May 22, 2021

Accepted on: September 16, 2021

Corresponding author: Juliana Ferreira da Costa Vargas Av. Cândido Hartmann 1712, Mercês. Zip code: 80710-570 - Curitiba, PR, Brazil E-mail: julianavargas_@hotmail.com

Institution: Hospital Universitário Evangélico Mackenzie, Curitiba, PR, Brazil.

Conflict of interest: no conflict of interest. Financial support:
the authors received no financial support for this work.

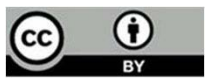

Copyright (C2022

\section{ABSTRACT}

Objective: To describe the use of subconjuctival administration of the anti-tumor necrosis factor agent adalimumab for treatment of dry eye in patients with Sjögren's syndrome, and to investigate conjunctival healing.

Methods: Prospective, nonrandomized, noncomparative interventional case series including consecutive patients with Sjögren's syndrome and dry eye disease treated with subconjunctival adalimumab, who were refractory to conventional treatment. Patients with infectious ocular surface involvement or structural changes in the tear pathway or eyelids were excluded. Data recorded included age, sex, lissamine green staining pattern, Schirmer test results, intraocular pressure, conjunctival mobility, tear break up time and findings of biomicroscopic evaluation, following fluorescein dye instillation. The Ocular Surface Disease Index questionnaire validated for the Portuguese language was used for subjective assessment of patients.

Results: Eleven eyes of eight patients were studied. Mean patient age was $53 \pm 13.4$ years. Patients were treated with subconjunctival injection of $0.03 \mathrm{~mL}$ of adalimumab and followed for 90 days thereafter There were no statistically significant objective improvement (objective tests results; $p>0.05$ ) and no statistically significant changes in intraocular pressure $(p=0.11)$. Questionnaire responses revealed a significant improvement in ocular symptoms ( $p=0.002)$.

Conclusion: Based on the Ocular Surface Disease Index questionnaire, subconjunctival administration of adalimumab improved dry eye symptoms. However, objective assessments failed to reveal statistically significant improvements.

\section{RESUMO}

Objetivo: Descrever o uso subconjuntival do antifator de necrose tumoral adalimumabe para o tratamento do olho seco em pacientes com síndrome de Sjögren e avaliar a cicatrização conjuntival.

Métodos: Série de casos intervencionista com desenho prospectivo, não randomizado, não comparativo. O medicamento adalimumabe foi aplicado em região subconjuntival em pacientes com síndrome de Sjögren e olho seco que eram resistentes a outras terapias convencionais. Pacientes com patologias oculares de origem infecciosa ou com alterações estruturais nas vias lacrimais e pálpebras foram excluídos do estudo. Os dados coletados incluíram idade, sexo, teste com lisamina verde, teste de Schirmer, pressão intraocular, mobilidade conjuntival, teste de ruptura do filme lacrimal, e avaliação biomicroscópica com colírio de fluoresceína. Além disso, o questionário Ocular Surface Disease Index validado para a língua portuguesa foi aplicado com objetivo de avaliar subjetivamente a resposta dos pacientes ao tratamento.

Resultados: Onze olhos de oito pacientes foram estudados. A idade média dos pacientes foi de 53 $\pm 13,4$ anos. A dose aplicada de adalimumabe subconjuntival foi de $0,03 \mathrm{~mL}$, e a duração do seguimento foi de 90 dias após a injeção. Não houve melhora estatisticamente significativa nos testes objetivos (todos apresentaram $p>0,05$ ). A pressão intraocular também não sofreu variações estatisticamente significativas $(p=0,11)$. Entretanto, por meio do questionário, foi registrada melhora significativa dos sintomas oculares $(p=0,002)$.

Conclusão: $\bigcirc$ uso do adalimumabe subconjuntival melhorou os sintomas de olho seco, avaliados por meio do questionário Ocular Surface Disease Index, mas não houve melhora estatisticamente significativa na avaliação objetiva. 


\section{INTRODUCTION}

Sjögren's syndrome is an autoimmune disease that affects the exocrine glands and is characterized by replacement of healthy tissue with lymphocytic infiltrate. ${ }^{(1)}$ Glandular dysfunction induced by this lymphocytic infiltrate decreases secretion, leading to dry mouth and dry eye symptoms. ${ }^{\left({ }^{1}\right)}$ Sjögren's syndrome is estimated to affect seven per 100,000 people. However, 47 per 100,000 people may be affected in some European and Asian countries, where the incidence is higher. ${ }^{(2)}$ According to the Sjögren's Foundation, dry eye is the most detrimental and limiting symptom reported by patients with Sjögren's syndrome, among other manifestations of the disease. ${ }^{(3)}$

Dry eye can be defined as a multifactorial condition associated with changes in the tear pathway and ocular surface. In the past, dry eye was defined as a tear film disorder caused by low tear production or excess of tear evaporation. ${ }^{(4)}$ However, dry eye etiology is now known to involve the disruption of tear film homeostasis, possibly due to hyperosmolarity, eye surface inflammation and damage or neurosensory abnormalities. ${ }^{(4-6)}$ Homeostasis must be maintained to lubricate and protect the eye surface. It also contributes to good visual acuity due to the corneal surface regularity provided by the tear film, which enhances refractive power. ${ }^{(7)}$ Other symptoms associated with this disorder include discomfort and visual disturbance, which are described by patients with dry eye disease (DED) as burning, foreign body sensation, itching, pain and blurred vision. ${ }^{(3)}$

In patients with Sjögren's syndrome, dry eye treatment often requires more efficient methods, ${ }^{(1)}$ since traditional approaches tend to fail due to lack of tear production and inflammation. At first, eye drops such as lubricants, autologous serum, diquafosol sodium, non-steroidal anti-inflammatory drugs, corticosteroids, cyclosporine and tacrolimus are recommended. ${ }^{(1,8)}$ Local non-pharmacological therapies, such as punctal occlusion with plugs or other techniques, contact lens and pulsed light treatment, are other therapeutic alternatives. ${ }^{(1,8,9)}$ Systemic treatment with the secretagogues pilocarpine and cevimeline was associated with statistically significant improvement in randomized controlled trials. However, a variable percentage of patients treated with these drugs experience side effects such as sweating, gastrointestinal discomfort, headache and nausea. ${ }^{(10-12)}$ Therefore, they cannot be used in many patients with severe dry eye, even when topical therapeutic alternatives have failed.

Several biologic drugs are used systemically to control the inflammatory reaction in patients with Sjögren's syndrome and other autoimmune diseases. Some biologic agents have anti-tumor necrosis factor alpha (TNF- $\alpha$ )-like properties. These agents block the binding of TNF to lymphocyte receptors, preventing subsequent changes in cellular immunity and avoiding tissue damage and cell apoptosis. Certolizumab, pegol, etanercept, infliximab, adalimumab and golimumab are examples of anti-TNF- $\alpha$ drugs. ${ }^{(13)}$

The role of TNF and interleukins in the pathogenesis of ocular inflammation has been demonstrated in several studies. Inhibition of these factors suppresses macrophage infiltration and decreases tissue damage, mitigating the inflammatory process associated with dry eye. ${ }^{(14,25)}$ Intravenous administration of infliximab and subcutaneous administration of adalimumab have been tested and shown to be effective in eye diseases such as refractory uveitis and cystoid macular edema. ${ }^{(16-19)}$ Intravenous administration of rituximab (anti-CD2O) and subcutaneous administration of etanercept have been used in dry eye patients, specifically in those with Sjögren's syndrome. However, improvement has not been objectively demonstrated. ${ }^{(20-23)}$

Topical use of anti TNF- $\alpha$ drugs has not been appropriately investigated. In some case series, intravitreal injection of adalimumab and infliximab have led to a significant improvement in ocular inflammation in patients with noninfectious uveitis. ${ }^{(24-28)}$

This study set out to examine the effectiveness of subconjunctival administration of adalimumab in patients with severe refractory DED due to Sjögren's syndrome.

\section{METHODS}

Prospective, nonrandomized, noncomparative interventional case series including patients with Sjögren's syndrome referred from the Rheumatology or Ophthalmology Clinic of Hospital Universitário Evangélico Mackenzie due to dry eye disease refractory to conventional treatments. All patients had been diagnosed with Sjögren's syndrome and had been experiencing persistent DED signs and symptoms ever since, in spite of treatment with lubricants, anti-inflammatory and corticosteroid eyedrops. Oral pilocarpine and topical autologous serum (two and one patient respectively) had also been used unsuccessfully. Treatment with cyclosporine, tacrolimus or punctal occlusion had not been attempted. Selected patients had controlled underlying disease and were undergoing systemic therapy. This study was approved by the hospital ethics committee and informed consent was obtained. Patients with infectious ocular surface involvement, structural lacrimal pathway and eyelid changes, wearing contact lens or submitted to prior ocular surgeries were excluded. 


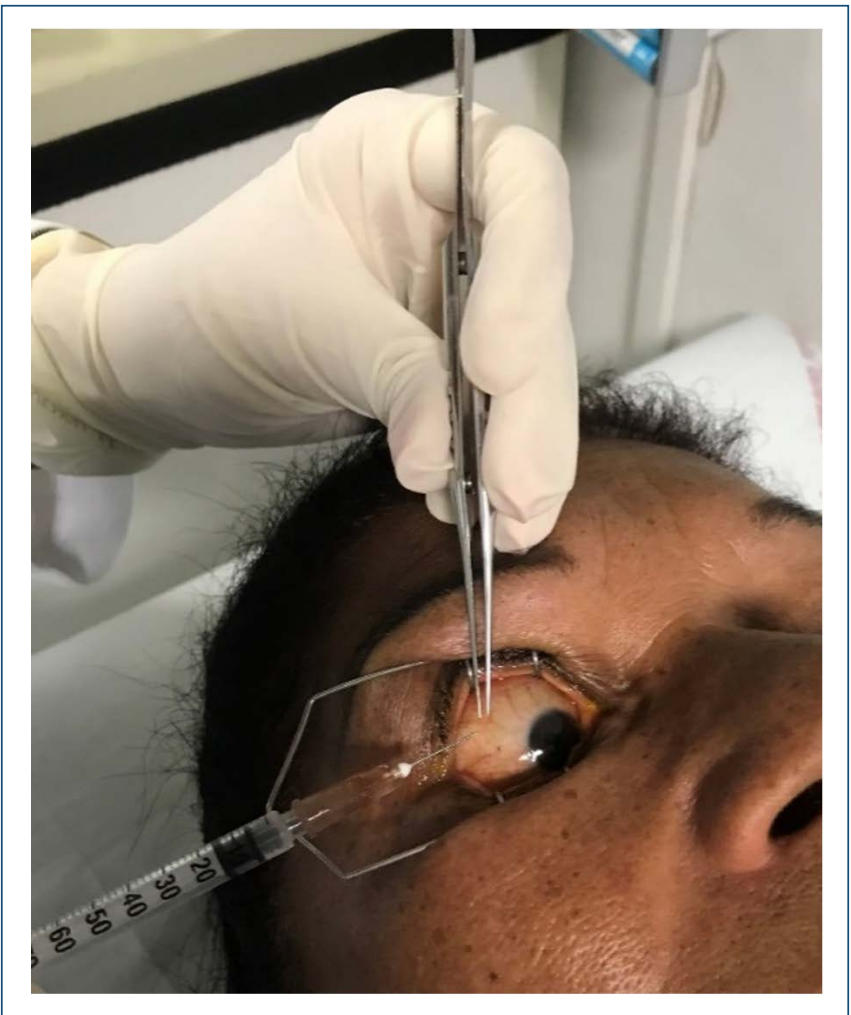

Figure 1. Adalimumab injection into the temporal subconjunctival space.
All other treatments (anti-inflammatory and corticosteroid eyedrops, pilocarpine and autologous serum) were discontinued prior to adalimumab administration, except lubricants eyedrops, which were maintained as necessary. Following instillation of one drop of $0.4 \%$ oxybuprocaine eye drop (Oxinest ${ }^{\circledR}$, Cristalia Produtos Químicos Farmacêutics, Cotia, SP, Brazil), 0.03 mL (1.5 mg) of fresh adalimumab (Humira ${ }^{\circledR}$, Abbott Laboratories, Abbott Park, IL, United States) were injected into the temporal subconjunctival space using a $26 \mathrm{G}$ x $13 \mathrm{~mm}$ needle (Figure 1).

Subjective assessment was based on the standard Ocular Surface Disease Index (OSDI) questionnaire validated for the Portuguese language (Figure 2). ${ }^{(29)}$ This questionnaire comprises 12 questions graded from zero to four, with a total score ranging from zero to one hundred, where higher values indicate more severe symptoms. The final score is calculated as summed scores x 25/number of questions answered. Based on scores, dry eye symptoms are categorized as normal (zero to 12), mild (13 to 22), moderate (23 to 32) or severe (greater than or equal to 33). Patients answered the questionnaire prior to and 28 days after adalimumab administration.

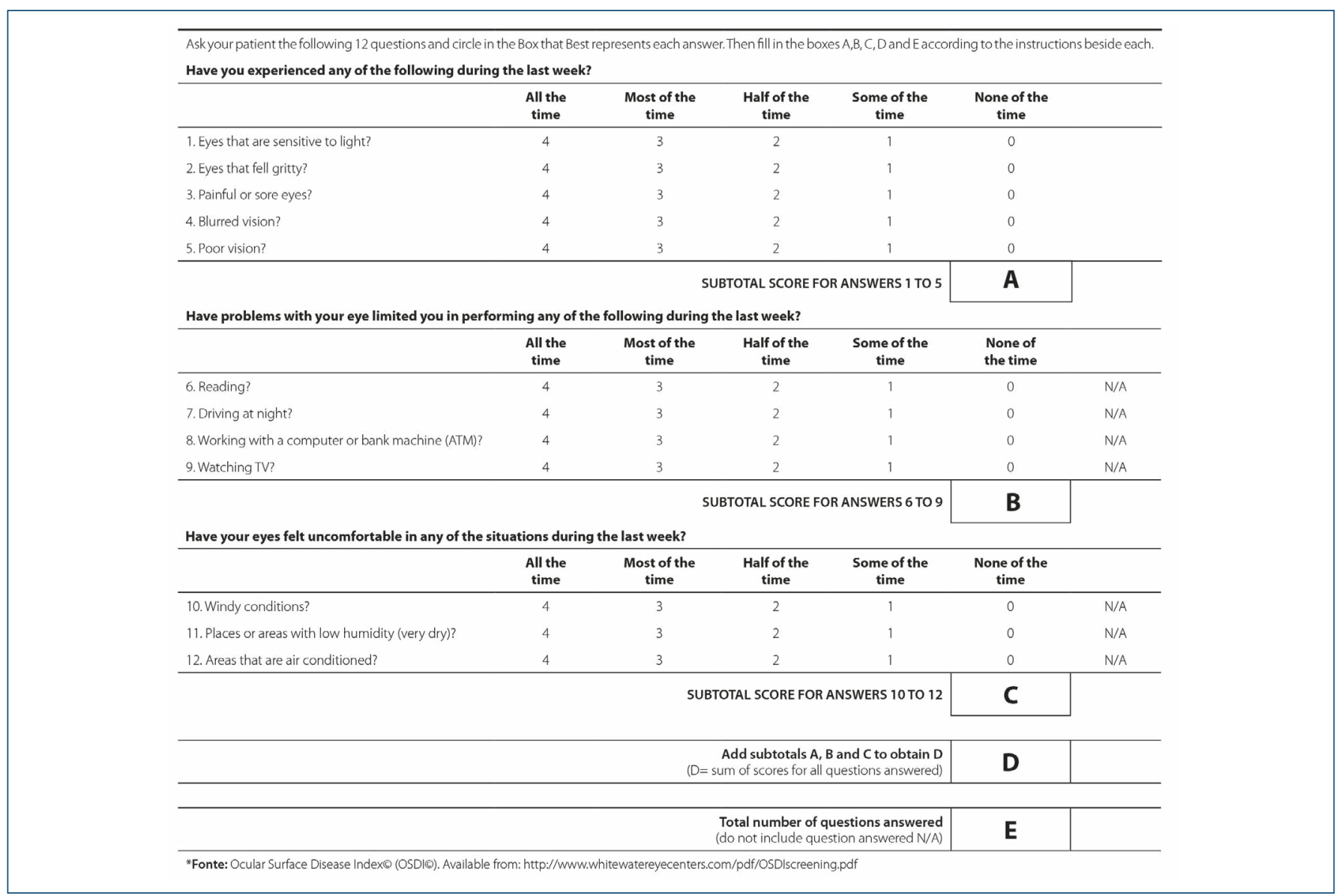

Source: Prigol AM, Tenório MB, Matschinske R, Gehlen ML, Skare T. Tradução e validação do índice da doença da superfície ocular para a língua portuguesa. Arq Bras Oftalmol. 2012;75(1):24-8.

Figure 2. Ocular surface disease index. 
Objective evaluation consisted of four ophthalmic exams. The ocular surface was submitted to biomicroscopic assessment following fluorescein dye instillation. Staining was graded one (no keratitis) to four (diffuse keratitis)(Figure 3).

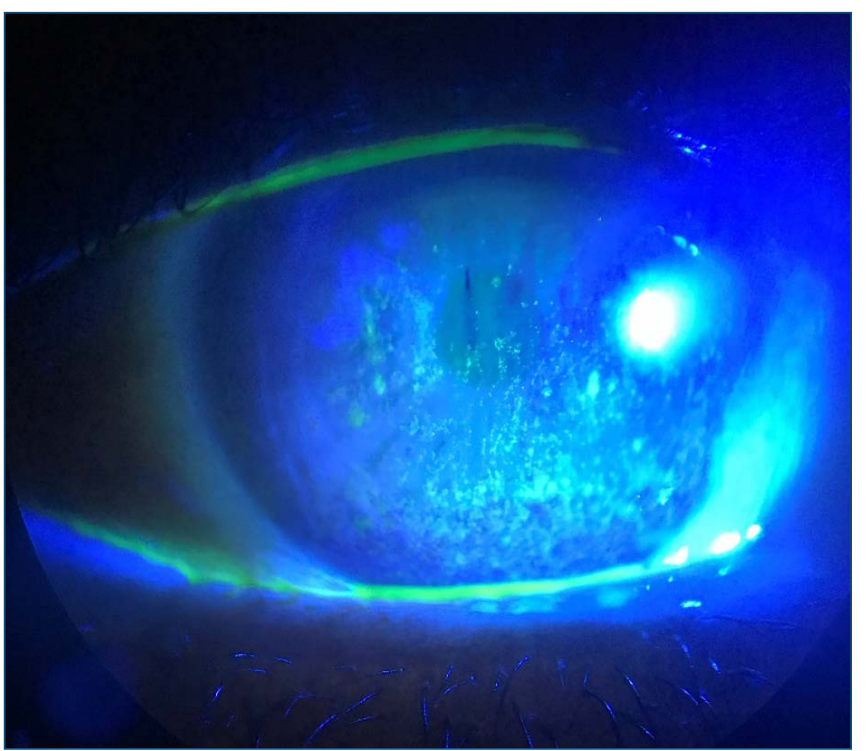

Figure 3. Biomicroscopic assessment of the ocular surface after fluorescein dye instillation.

The tear break-up time (TBUT) test was then performed. This test consists of tear film assessment using a cobalt light following instillation of one drop of fluorescein dye. Test results are considered normal whenever the tear film remains uniform for at least 10 seconds. Tear film discontinuity within less than 10 seconds is interpreted as tear instability, which may be due to dry eye or ocular surface irregularity. ${ }^{(30)}$ The third test consisted of lissamine green staining for conjunctival integrity assessment. This test detects dry eye occurrence and severity by positive staining. ${ }^{(30)}$ Staining is graded using a one-to-four scale, where one equals no staining and four means dye is found throughout the conjunctival surface. Finally, the Schirmer test I was used for tear secretion quantification. In this test, a paper strip is placed on the lower eyelid and measured in millimeters after 5 minutes. Strip wetting of less than $10 \mathrm{~mm}$ indicates dry eyes. ${ }^{\left({ }^{30}\right)}$ Conjunctival mobility was tested using a conjunctival forceps placed at the injection site in order to determine the ability of the drug to induce healing. Intraocular pressure (IOP) was measured using a Goldman tonometer to check for variations after adalimumab administration. Tests were performed in sequence to prevent potential interfere with test results.
The Schirmer test was performed first. The ocular surface was then evaluated. This was followed by the TBUT test, lissamine green staining and IOP measurement.

Patients were examined weekly after subconjunctival adalimumab injection for 1 month, then reexamined within 2 and 3 months. Objective and subjective tests were carried out by the same examiner on all occasions.

Data were collected and analyzed using frequency tables. Do (day o - prior to adalimumab injection) values were compared with D7, D14, D21, D28, D60 and D90 values (seven, fourteen, twenty-one, twenty-eight, sixty and ninety days after adalimumab injection) using the Friedman test (more than two repeated measures with non-Gaussian distribution). Repeated numerical measures (data collected using the OSDI questionnaire) were compared using the Wilcoxon test. Nominal data were compared using the chi-square test. Frequencies were expressed as percentages. Measures of central tendency were expressed as means and standard deviations (SD) (measures) with Gaussian distribution) or median and interquartile ranges (IQR) (measures with non-Gaussian distribution). Data distribution was examined using the Shapiro-Wilk test. The level of significance was set at 5\%. Calculations were made using Graph Pad Prism software, version 6.01.

This project was approved by the Research Ethics Committee of Evangelical Mackenzie University Hospital (Registration number in Platform Brazil, CAAE: 87172118.2.0000.0103)

\section{RESULTS}

Eleven eyes of eight patients with a mean age of $53 \pm 13.4$ years (26 to 68 years) were studied. All patients were women (100\%). Four patients (six eyes, 54.5\%) had primary Sjögren's syndrome, three patients (four eyes, 36.3\%) had secondary Sjögren's syndrome due to rheumatoid arthritis and one patient (one eye, 9\%) had Sjögren's syndrome secondary to juvenile idiopathic arthritis. In all cases, patients were receiving systemic treatments for their respective underlying diseases, which were appropriately controlled (Table 1).

Table 1. Systemic medications used by patients

\begin{tabular}{lc} 
Systemic Medicine & Patients \\
\hline Rituximab & $3(37.5)$ \\
Antimalarial & $3(37.5)$ \\
Anti-TNF alpha & $1(12.5)$ \\
Methotrexate & $2(25.0)$ \\
Leflunomide & $1(12.5)$ \\
Prednisone & $3(37.5)$ \\
\hline
\end{tabular}

Results expressed as $n(\%)$. TNF: tumor necrosis factor 


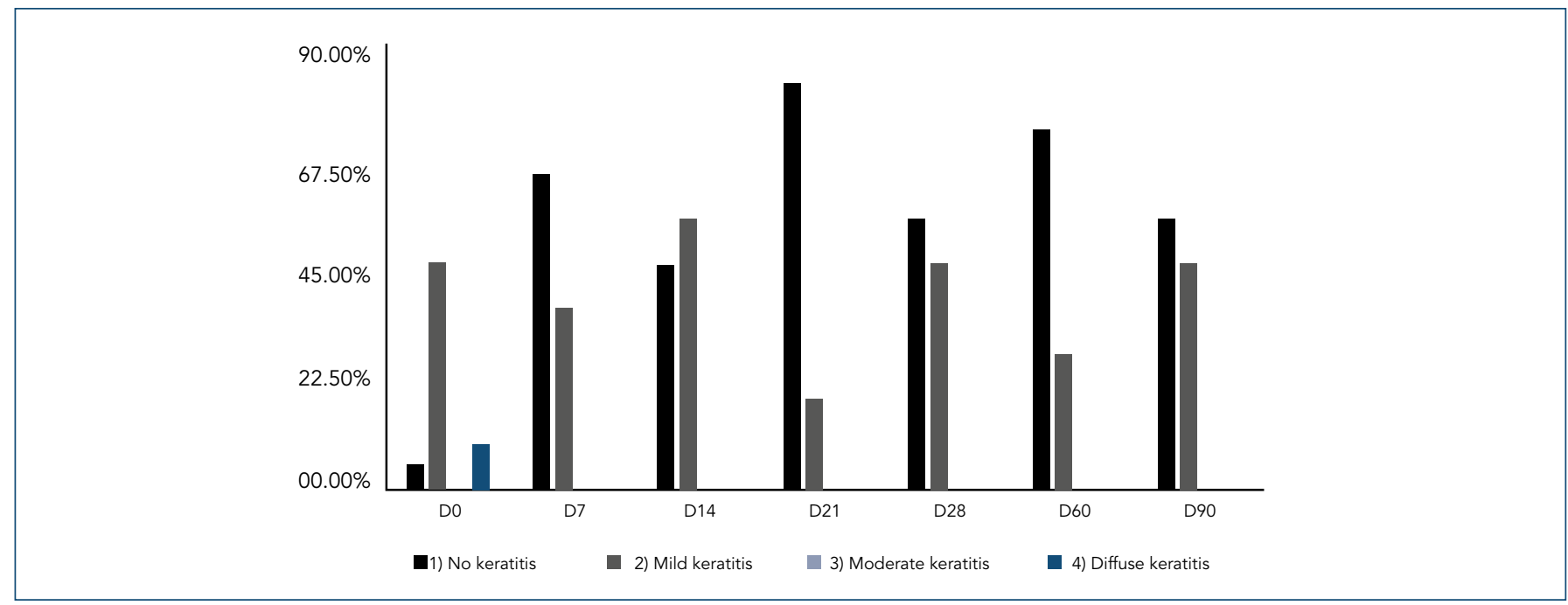

Figure 4. Comparison of ocular surface findings across the different assessment time points.

All patients required more than one medication for underlying disease control.

Of 11 patients who started treatment, one was lost to follow-up after day 28, one had conjunctivitis on day 21 and was prescribed a combination of tobramycin $(3 \mathrm{mg} /$ $\mathrm{mL}$ ) and dexamethasone (1 mg/mL) for 1 week and one developed spontaneous perforation after day 47 and required penetrating keratoplasty. These patients were excluded from the study.

Subjective assessment based on OSDI questionnaire responses indicated a significant improvement in eye symptoms, with a median pre-treatment value of 87.5 (IQR 60.5-90.5) and a median value of 54.1 (IQR 22.8-55.8) 28 days after adalimumab administration $(\mathrm{p}=0.002)$. All patients reported improvement in DED symptoms and therefore reduced the use of lubricants. However, objective tests failed to reveal statistically significant improvements (Table 2). On ocular surface evaluation, signs of keratitis were detected in six eyes (54.5\%) prior to injection and in five eyes (45.5\%) after day 90, whereas six eyes (54.5\%) did not have signs of keratitis $(p=0.74$; Chi-squared test). According to staining grade, five eyes
(45.5\%) did not have signs of keratitis, five $(45.5 \%)$ had mild keratitis (grade 2 ) and one (9.1\%) had diffuse keratitis (grade 4). Improvements were noted on D21, since nine eyes (81.8\%) had no signs of keratitis and two (18.2\%) had mild keratitis. Comparative analysis of Do and D9o findings failed to reveal significant improvements (Figure 4).

TBUT test results improved from 4 to 5 seconds (IQR 1.0-5.0 and QR 2.25-7.5 respectively; $\mathrm{p}=0.22$; Friedman test). Lissamine green staining revealed positive conjunctival staining and mucus in seven eyes. Prior to treatment, staining was graded mild in six eyes (grade 2; 63.6\%) and moderate in one eye (grade 3). At the end of treatment (D9o) only six eyes (54.5\%) showed positive staining, which was graded mild in all cases ( $p=0.57$; Chi-squared test). The Schirmer test I revealed a median of $5 \mathrm{~mm}$ (IQR 1.0-15.0) prior to adalimumab administration, which increased to $6 \mathrm{~mm}$ (IQR 1.08.0) on D6o and decreased to $3 \mathrm{~mm}$ (IQR 2.0-8.0) on D9o $(\mathrm{p}=0.55$; Friedman test). Conjunctival mobility remained unchanged following adalimumab administration, despite conjunctival hemorrhage at the injection site in two eyes. Pre- and post-treatment IOP values did not differ significantly (median 10, IQR 10-12, p=0.11; Friedman test) (Table 2) .

Table 2. Objective tests results

\begin{tabular}{|c|c|c|c|c|c|c|c|c|}
\hline & \multicolumn{7}{|c|}{ Day } & \multirow{2}{*}{$p$-value } \\
\hline & Do & D7 & D14 & D21 & D28 & D60 & D90 & \\
\hline Number of eyes & 11 & 11 & 11 & 11 & 11 & 11 & 11 & \\
\hline Ocular surface* & $6(54.5)$ & $4(36.36)$ & $6(54.5)$ & $2(18.2)$ & $5(45.5)$ & $3(27.3)$ & $5(45.5)$ & 0.74 \\
\hline TBUT, seconds & $4(1-5)$ & $4(1.5-10)$ & $5(4-7)$ & $5(3-10)$ & $4(2.25-9.25)$ & $5(3.25-9.25)$ & $5(2.25-7.5)$ & 0.22 \\
\hline Lissamine green staining $†$ & $7(63.6)$ & & & & & & $6(54.5)$ & 0.57 \\
\hline Schirmer test I, mm & $5(1-15)$ & $6(1-9)$ & $5(3-8)$ & $8(1-10)$ & $4(1-6)$ & $6(1-8)$ & $3(2-8)$ & 0.55 \\
\hline IOP, $\mathrm{mmHg}$ & $10(10-12)$ & $10(10-12)$ & $10(10-10)$ & $10(8-12)$ & $10(8-10)$ & $10(10-12)$ & $10(10-12)$ & 0.11 \\
\hline
\end{tabular}

Results expressed as $n(\%)$ or median (interquartile range).

More than one variable was examined on ocular surface assessment and the lissamine green staining test. Therefore, median values were not presented.

Results obtained in the TBUT and the Schirmer test I, and IOP measurements were expressed as median values and IQR (non-parametric statistics: variables with non-Gaussian distribution).

* Number of eyes with signs of keratitis; tnumber of eyes with positive conjunctival staining.

TBUT: tear breakup time test; IOP: Intraocular pressure 


\section{DISCUSSION}

In patients with Sjögren's syndrome, secondary dry eye disease accounts for high morbidity and resultant loss of quality of life due to symptoms such as burning, foreign body sensation, itching, pain and blurred vision. ${ }^{(3)}$ In spite of the numerous treatment alternatives for DED, many patients experience side effects or are refractory to conventional therapy.

In this study, subconjunctival injection of adalimumab had no significant positive impacts on selected objective parameters. However, symptom alleviation was achieved.

The topical use of adalimumab for dry eye treatment of has not been investigated so far. However, clinical improvement in treated patients may be attributed to the anti-inflammatory effects of this drug, which has been shown the increase the levels of pro-inflammatory cytokines such as interleukin (IL) $1 \alpha$, IL-6, IL-8, TNF- $\alpha$ and transforming growth factor (TGF) $\beta$ in the conjunctival epithelium of patients with Sjögren's syndrome ${ }^{(31)}$ and the levels of IL- 6 and TNF- $\alpha$ in the tear of patients with dry eye. ${ }^{(32)}$ Adalimumab blocks the activity of TNF- $\alpha$ and inhibits the binding of this cytokine to TNFR-1 and TNFR-2, preventing the perpetuation of the inflammatory, apoptotic and cell proliferating cascade. ${ }^{(33,34)}$ Systemic treatment with the anti-TNF agent etanercept and the anti-CD20 biological agent rituximab have been investigated. Lack of objective improvement in patients with dry eye and Sjögren's syndrome suggests these agents do not reach therapeutic levels on the ocular surface when used subcutaneously or intravenously (etanercept and rituximab respectively). ${ }^{(20-23)}$ Also, although this cannot be extrapolated to humans, Li et al. ${ }^{(35)}$ have shown that topical use of infliximab in rats with experimentally induced dry eye led to enhanced tear production and decreased levels of the inflammatory cytokines IL-1 $\beta$, IL-6, IL-17 and IFN - $\gamma$ in the conjunctiva.

Like biological agents, the anti-inflammatory effects of corticosteroids are also associated with inhibition of cytokines, such as IL-1, IL-6, IL-8, TNF- $\alpha$, granulocyte-macrophage colony-stimulating factor (GM-CSF), and metalloproteinase-9 (MMP-9) in the corneal epithelium. ${ }^{(36)}$ Many studies have shown that short-term use of corticosteroids is an effective inflammatory reaction reaction control and DED treatment. strategy. ${ }^{(3)}$ However, chronic or intermittent use of corticosteroids may have negative effects, such as increased IOP, cataract development and opportunistic infections. ${ }^{(37)}$

In this study, no side effects were reported by treated patients, aside from conjunctival hemorrhage following adalimumab administration in two cases. Intraocular pressure remained unchanged and no significant healing occurred, as shown by preserved conjunctival mobility and lack of conjuctival scar tissue or adhesion formation. However, one patient developed conjunctivitis and another sustained spontaneous corneal perforation. The latter patient had been diagnosed with corneal thinning prior to subconjunctival injection of adalimumab and his contralateral eye had already been treated for spontaneous perforation. Although this patient had achieved systemic control, he still suffered from severe dry eye, in spite of having tried different therapies, such as lubricants, autologous serum, topic corticosteroids and pilocarpine. Adalimumab injection improved his Schirmer test results. However, corneal thinning persisted throughout the follow-up period preceding eye perforation. Authors of this study believe this was a naturally occurring process. Still, the hypothesis that subconjunctival injection may have accelerated progression cannot be ruled out. Both patients were excluded from the study, since use corticosteroid eye drops may have interfered with the inflammatory response.

The half-life of adalimumab administered by subcutaneous injection is 14 days. However, the concentration of this drug in ocular tissues has not been measured. Adalimumab is widely used for systemic treatment of rheumatoid arthritis and is thought to be safe in these settings, even though it may increase the incidence of infections as tuberculosis. ${ }^{(38)}$

Some studies had shown that subcutaneous administration of adalimumab may cause corneal infiltrates or uveitis. However, evidence is lacking, given these conditions may result from the underlying disease. Also, the aforementioned studies consisted of a case report and a case series, respectively. ${ }^{(39,40)}$

\section{CONCLUSION}

In conclusion, treatment with subconjunctival injection of adalimumab was associated with a statistically significant subjective improvement in symptoms and numerical (i.e., non-significant) improvement in parameters such as tear break-up time, fluorescein staining pattern and lissamine green test and Schirmer test results. No significant local side effects were detected, and intraocular pressure remained unchanged during treatment.

This study has some limitations, such as small sample size. This is understandable, since an experimental form of treatment was proposed to patients. Also, the effects of anti-tumor necrosis factor alpha in dry eye disease were 
investigated for a short period of time. Therefore, safety profile-related findings cannot be extrapolated to longterm treatment. Dry eye disease treatment in patients with Sjögren's syndrome using subconjunctival administration adalimumab requires further investigation, with a larger number of patients, for appropriate assessment of clinical effectiveness and immunobiological parameters.

\section{AUTHORS" CONTRIBUTION}

Juliana Ferreira da Costa Vargas: data collection, writing of the manuscript; Thelma Skare: conception of the study, data interpretation; Marcelo Luiz Gehlen: conception and design of the study; Ana Tereza Ramos Moreira: writing of the manuscript, critical revision of the content.

\section{REFERENCES}

1. Shih KC, Lun CN, Jhanji V, Thong BY, Tong L. Systematic review of randomized controlled trials in the treatment of dry eye disease in Sjogren syndrome. J Inflamm (Lond). 2017;14:26.

2. Qin BW, Yang Z, Yang M, Ma N, Huang F, Zhong R. Epidemiology of primary Sjogren's syndrome: a systematic review and meta-analysis. Ann Rheum Dis. 2015;74(11):1983-9.

3. Foulks GN, Forstot SL, Donshik PC, Forstot JZ, Goldstein MH, Lemp $M A$, et al. Clinical guidelines for management of dry eye associated with Sjögren disease. Ocul Surf. 2015;13(2):118-32

4. Craig JP, Nichols KK, Akpek EK, Caffery B, Dua HS, Joo CK, et al. TFOS DEWS II Definition and Classification report. Ocul Surf. 2017;15(3):276-83.

5. Tomlison A, Khanal S, Ramaesh K, Diaper C, McFadyen A. Tear film osmolarity: determination of a referent for dry eye diagnosis. Invest Ophtahalmol Vis Sci. 2006;47(10):4309-15.

6. Bron AJ. Diagnosis of dry eye. Surv Ophthalmol. 2001; 45(Suppl 2): S2216.

7. Willcox MD, Argüeso P, Georgiev G, Holopainen J, Laurie G, Millar T, et al. TFOS DEWS II Tear Film report. Ocul Surf. 2017;15(3):366-403.

8. Jones L, Downie LE, Korb D, Benitez-del-Castillo JM, Dana R, Deng SX, et al. TFOS DEWS II Management and Therapy report. Ocul Surf. 2017;15(3):580-634.

9. Arita R, Fukuoka S, Morishige N. Therapeutic efficacy of intense pulsed light in patients with refractory meibomian gland dysfunction. Ocul Surf. 2019;17(1):104-10.

10. Tsifetaki N, Kitsos G, Paschides CA, Alamanos Y, Eftaxias V, Voulgari PV, et al. Oral pilocarpine for the treatment of ocular symptoms in patients with Sjögren's syndrome: a randomised 12 week controlled study. Ann Rheum Dis. 2003;62(12):1204-7

11. Petrone D, Condemi JJ, Fife R, Gluck O, Cohen S, Dalgin P. A doubleblind, randomized, placebo-controlled study of cevimeline in Sjögren's syndrome patients with xerostomia and keratoconjunctivitis sicca. Arthritis Rheum. 2002;46(3):748-54.

12. Ono M, Takamura E, Shinozaki K, Tsumura T, Hamano T, Yagi Y, et al. Therapeutic effect of cevimeline on dry eye in patients with Sjögren's syndrome: a randomized, double-blind clinical study. Am J Ophthalmol. 2004; 138(1):6-17

13. Leal I, Rodrigues FB, Sousa DC, Romão VC, Duarte GS, Carreño $E$, et al. Efficacy and safety of intravitreal anti-tumour necrosis factor drugs in adults with non-infectious uveitis - a systematic review. Acta Ophthalmol. 2018;96(6):665-75.

14. Murray PI, Sivaraj RR. Anti-TNF-alpha therapy for uveitis: Behcet and beyond. Eye (Lond). 2005;19(8):831-3.

15. Robertson M, Liversidge J, Forrester JV, Dick AD. Neutralizing tumor necrosis factor-alpha activity suppresses activation of infiltrating macrophages in experimental autoimune uveoretinitis. Invest Ophthalmol Vis Sci. 2003;44(7):3034-41.

16. Sobrin L, Kim EC, Christen W, Papadaki T, Letko E, Foster S. Infliximab therapy for the treatment of refractory ocular inflammatory disease. Arch Ophthalmol. 2007;125(7):895-900

17. Dobner BC, Max R, Becker MD, Heiz C, Veltrup I, Heiligenhaus A, et al. A three-centre experience with adalimumab for the treatment of noninfectious uveitis. Br J Ophthalmol. 2013;97(2):134-8.

18. Diaz-Llopis M, Garcia-Delpech S, Salom D, Udaondo P, Hernández-Garfella $\mathrm{M}$, Bosch-Morell F, et al. Adalimumab therapy for refractory uveitis: a pilot study. J Ocul Pharmacol Ther. 2008;24(3):351-61.

19. Díaz-Llopis M, Salom D, Garcia-de-Vicuña C, Cordero-Coma M, G, Ortego $N$, et al. Treatment of refractory uveitis with adalimumab: a prospective multicenter study of 131 patients. Ophthalmology. 2012;119(8):1575-81.

20. Brown S, Navarro Coy N, Pitzalis C, Emery P, Pavitt S, Gray J, Hulme C, Hall F, Busch R, Smith P, Dawson L, Bombardieri M, Wan-Fai N, Pease C, Price E, Sutcliffe N, Woods C, Ruddock S, Everett C, Reynolds C, Skinner E, Poveda-Gallego A, Rout J, Macleod I, Rauz S, Bowman S; TRACTISS trial team. The TRACTISS protocol: a randomised double blind placebo controlled clinical trial of anti-B-cell therapy in patients with primary Sjögren's Syndrome. BMC Musculoskelet Disord. 2014;15:21.

21. Devauchelle-Pensec V, Mariette X, Jousse-Joulin S, Berthelot JM, Perdriger A, Hachulla E, et al. OP0065 tolerance and efficacy of rituximab in primary sjogren syndrome (TEARS): results of a randomized controlled trial. Ann Rheum Dis. 2014;71(Suppl 3):75.71-5.

22. Devauchelle-Pensec V, Mariette X, Jousse-Joulin S, Berthelot JM, Perdriger A, Puéchal $X$, et al. Treatment of primary Sjögren syndrome with rituximab. Ann Intern Med. 2014;160(4):233-42.

23. Sankar V, Brennan MT, Kok MR, Leakan RA, Smith JA, Manny J, et al. Pillemer SR. Etanercept in Sjögren's syndrome: a twelve-week randomized, doubleblind, placebo-controlled pilot clinical trial. Arthritis Rheum. 2004;50(7):2240-5.

24. Androudi S, Tsironi E, Kalogeropoulos C, Theodoridou A, Brazitikos P. Intravitreal adalimumab for refractory uveitis-related macular edema. Ophthalmology. 2010;117(8):1612-6.

25. Farvardin M, Afarid M, Mehryar M, Hosseini H. Intravitreal infliximab for the treatment of sight-threatening chronic noninfectious uveitis. Retina. 2010;30(9):1530-5.

26. Markomichelakis N, Delicha E, Masselos S, Sfikakis PP. Intravitreal infliximab for sight-threatening relapsing uveitis in Behçet disease: a pilot study in 15 patients. Am J Ophthalmol. 2012;154(3):534-541.e1.

27. Hamza MM, Macky TA, Frcse D, Sidky MK. Intravitreal infliximab in refractory uveitis in Behcet's disease A Safety and Efficacy clinical Study. Retina. 2016;36(12):2399-408.

28. Hamam RN, Barikian AW, Antonios RS, Abdulaal MR, Alameddine RM, Mollayess G, et al. Intravitreal adalimumab in active noninfectious uveitis: a pilot study, ocular immunology and inflammation. 2016;24(3):319-26.

29. Prigol AM, Tenório MB, Matschinske R, Gehlen ML, Skare T. Tradução e validação do índice da doença da superfície ocular para a língua portuguesa. Arq Bras Oftalmol. 2012;75(1):24-8.

30. Bron AJ, Abelson MB, Ousler G, Pearce E, Tomlinson A, Yokoi N, et al. Methodologies to diagnose and monitor dry eye disease: Report of the diagnostic methodology subcommittee of the international Dry Eye Workshop (2007). Ocular Surface. 2007;5(2):108-52.

31. Pflugfelder SC, Jones D, Ji Z, Afonso A, Monroy D. Altered cytokine balance in the tear fluid and conjunctiva of patients with Sjögren's syndrome keratoconjunctivitis sicca. Curr Eye Res. 1999;19(3):201-11.

32. Yoon KC, Jeong IY, Park YG, Yang SY. Interleukin-6 and tumor necrosis factor-alpha levels in tears of patients with dry eye syndrome. Cornea 2007;26(4):431-7.

33. Wajant H, Henkler F, Scheurich P. The TNF-receptor-associatedfactor family: scaffold molecules for cytokine receptors, kinasesand their regulators. Cell Signal. 2001;13(6):389-400.

34. Chen G, Goeddel DV. TNF-R1 signaling: a beautiful pathway. Science. 2002;296(5573):1634-5.

35. Li Z, Choi W, Oh HJ, Yoon KC. Effectiveness of topical infliximab in a mouse model of experimental dry eye. Cornea. 2012;31 Suppl 1:S25-S31. 
36. De Paiva CS, Corrales RM, Villarreal AL, Farley WJ, Li DQ, Stern ME, et al. Corticosteroid and doxycycline suppress MMP-9 and inflammatory cytokine expression, MAPK activation in the corneal epithelium in experimental dry eye. Experimental Eye Research. 2006;83(3):526-35.

37. Marsh P, Pflugfelder SC. Topical nonpreserved methylprednisolone therapy for keratoconjunctivitis sicca in Sjögren syndrome. Ophthalmology. 1999;106(4):811-6.
38. Murdaca G, Spanò F, Puppo F. Long-term treatment of rheumatoid arthritis with adalimumab. Open Access Rheumatol. 2013;5:43-9.

39. Matet A, Daruich A, Beydoun T, Cosnes J, Bourges JL. Systemic adalimumab induces peripheral corneal infiltrates: a case report. BMC Ophthalmol. 2015;15:57.

40. Lim LL, Fraunfelder FW, Rosenbaum JT. Do tumor necrosis factor inhibitors cause uveitis? A registry-based study. Arthritis Rheum. 2007;56(10):3248-52. 